\title{
Biomechanical Analysis of Bone Healing at One-Plate and Double- Plate Fixation of Femoral Bone Fractures
}

\author{
Jarosław Sidun \\ Bialystok Technical University, Mechanical Faculty, Wiejka 45c, 15-351 Bialystok
}

\begin{abstract}
The present paper present describes so-far unsolved issues of the biomechanics of the bone - plate stabiliser system functioning in a multi-plane system. The few available publications treat this question selectively and often generally. There are no reports which would provide data on the influence of the geometry of a Polfix type plate stabiliser system on the speed of the long bones synostosis process. Clinical practice shows that using an improperly selected fixation system and inappropriate biomechanical stabilisation conditions leads to an inappropriate course of the synostosis process. On the basis of distortion vector maps, the location of the system's rotation centre was determined. In the case of a one-plate fixation, its smaller rigidity and thus greater displacement in the fracture crack, makes it possible for rotation and lateral displacement to occur. This leads to shearing of the newly forming bone tissue. In the case of a two-plate fixation, the system's rotation centre is located in the fracture crack. This is the area where approximation of bone fractures takes place. The distribution scheme of the distortion vectors on the surface of the model shows that the system's rotation centre is located in the fracture crack, and axial approximation of the fixed fragments occurs in this area. Movements of such a type in the fracture crack stimulate callus formation.
\end{abstract}

\section{Introduction}

Along with the development of technology, mainly motorization and active lifestyle of a contemporary person, we can observe a substantial increase of a variety of injuries to organs responsible for locomotion. In the light of medical knowledge, in the cases of healing bone fractures it is essential to reduce the fracture and maintain it in such a position as to restore the functions of the injured body part until synostosis occurs. The most beneficial method is to obtain a stable fixation of the fractured bone, which enables the patient to undergo therapeutic rehabilitation as soon as possible. In the majority of clinical cases, difficulties are observed in long bone stabilisation with the use of widely applied osteosynthesis methods [1, 5, 9]. Excessive obesity, ankylosis, infected non-union of fragments with bone defects, mental diseases and the need to avoid the bone fractions rotation constitute an example complex of factors making it impossible to apply an ordinary plate, an intermarrow rod, or an external stabiliser in order to obtain stable fixation $[2,3]$.

The main direction of the research carried out in the work were the unsolved issues of the biomechanics of the bone - Polfix type plate stabiliser system functioning in a multi-plane system. The work includes an analysis of the influence of different plate 
fixation parameters on the state of the fixation's tensions and displacements with the use of a parametric numerical model as well as experiments on a physical model with the aim to establish the actual biomechanical characteristics $[4,6,10]$.

In order to facilitate physicians in the process of diagnosing, highly advanced computer systems are becoming more and more popular. CAE (Computer Aided Engineering) programmes are often used, allowing to analyse the model's operating with the load force imposed on it. An example of such a programme is ANSYS using the Finite Element Method (FEM). Some of the advantages of this type of research are its low costs and the possibility of carrying out research practically in all conditions. For a more complete description it is of course indispensable to carry out also experiments aiming at verification but the latter are easier to conduct in the presence of the first assessment resulting from the use of the numerical model.

\section{Materials and Methods}

On the basis of a literature analysis as well as clinical data, a parametrical numerical model of a two-plane plate femoral bone fixation was created. The model takes into consideration the following parameters: the bone diameter, the cortex layer thickness, the closer and farther fraction lengths, the interfragmental crack, the plates inclination angle, the lengths of the fixing plates, the distance between the plates and the bone, the angle of mounting of the first plate, and also the number, lengths, and diameters of the screws, as well as the distances between the latter.

The experiments were also carried out using ESPI (Electronical Spankl Photo Interferometry). This method uses the phenomena of reflection and diffusion of laser light on a rough surface of the tested object. ESPI method bases on registration of electronically acquired spot images, which enables for automatic processing of data about the state of dislocation of the tested surface.

Tests on animals were also carried out on approval of the Ethics Commission on Animal Experimentation and Didactics at the Rector of the Warsaw University of Life Sciences (Approval no. 9/98).

Three-year old castrated male goats weighing from 30 to $35 \mathrm{~kg}$, of unknown breed, were used in this study. The fixations were made with the use of Polfix type plates with screws of $4.5 \mathrm{~mm}$ in diam- eter. Pyralgin (Metamizole sodium) and Betamox (Amoxicillin trihidrate) were administered as intramuscular injections. The goats started to bear weight on their limbs one day after the operations. After a two-day period of being raised, the body temperature of the goats was normal again. The animals felt well throughout the whole observation period and were able to move well (slightly visible lameness at the walk, and when coming back to the stable, the goats trotted or galloped spontaneously).

During the research on the animals, $X$-ray imaging was performed at 2-week intervals. The obtained images were later analysed in order to assess synostosis. The idea of assessing the synostosis quality is based on the assumptions that an ideal bone structure should be continuous or it may change fluently only to a small extent. The developed algorithm analyses callus on the basis of observing the greyness level, comparing the structure of the formed callus to the structure of a healthy bone in a linear way along the bone axis. An ideal structure should be characterised by the histogram of greyness distribution which is rectilinear or close to rectilinear. The sudden fault in the histogram corresponds to structural differences in the fracture crack with respect to the fixed fractures $[7,8,12]$.

In order to reduce the possibility of artefacts appearing in the images, the radiograms are initially filtered with the use of a median filter. The function of this filter is to arrange the analysed point and the points of its neighbourhood in a sequence according to the increasing values of their greyness. The mean value of the sequence is then determined and assigned to the analysed image point $[8,12]$. A median filter rejects extreme values which are defined as noise. The callus formation coefficient may be determined from the following dependence [12]

$C_{\text {kostniny }}=\frac{\sum_{i=1}^{n} \frac{P_{r}(i)}{P_{s}(i)}}{n}$

where:

$\operatorname{Pr}(i)$-value in analysed callus image,

Ps(i) - i-th pixel value in simulated structure image, $\mathrm{n}$ - number of analysed pixel in analysed image. 


\section{Results}

The results obtained on the basis of the numerical simulations performed with the use of the FEM illustrate the tension and deformation fields distribution patterns. The obtained results confirm clinical data on loosening of the outermost screws of the plate stabilisers. The highest tension values were observed at the screw - first bone cortex layer boundary, i.e. the layer closest to the fixing plate. The above is confirmed by clinical reports informing on the observed loosening of the screws at these points.

a)
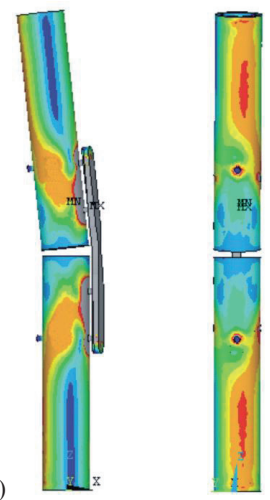

b)
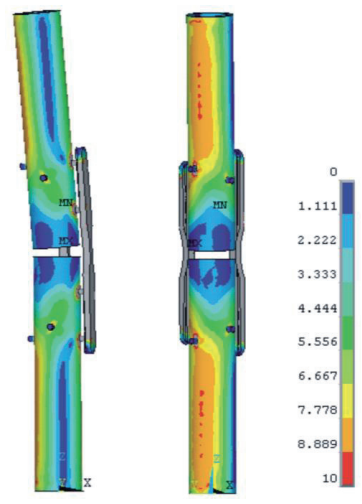

Fig. 1: Example results of numerical analysis: a) one-plane and, b) two-plane fixation.

An analysis of the test results using ESPI shows that application of double-plate stabilization in comparison to single-plate stabilization causes substantial decrease of lateral displacement of bone fragments in the area of the fracture gap, with a negligible change of axial displacement parameters. This can favourably affect the state of loads in a newly formed bone tissue in the fracture crack. Changing the length of the bone screw fixing stabilisers in the area of the fracture causes insignificant changes of the displacement state. It is important though to take under consideration that models of bone fractures are characterised by a greater stiffness in relation to the actual bone tissue. Examples of displacement test results using ESPI are presented in Figure 2.

Distribution of distortion vectors for one- twoplate fixation are presented in Figure 3. The obtained results presents advantageous distribution of distortion vector. From the point of view of biomechanics, bone fractions fixed with the use of a two-plane plate fixation constitute quite complex, dimensional constructions. The selection of the appropriate parameters in fixations of this type directly influences the stabiliser's rigidity, thus influencing the conditions of the callus formation and shape, the durability of the bone grown together, and in the final effect - the success of the whole operation. a)

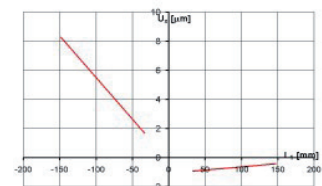

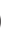
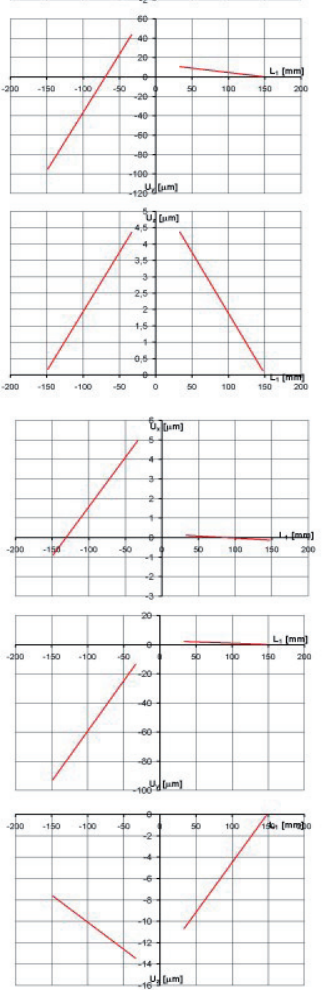
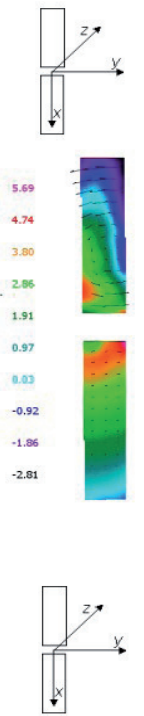

0.365

$-1.201$

$-2.768$

4.334

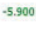

$-7.467$

$-9.033$

$-10.600$

$-12.166$

$-13.732$ b)

Fig. 2: Visualization of model's state of distortion in three axes with distortion vector map (eccentricity of load with $F 1+\Delta F$ force): a) one-plate stabilization, b) double-plate stabilization.

The clinical usefulness of the fixations was assessed on the basis of observation of the healing process with the radiologic method applying computer image analysis. For that end, an own method of processing X-ray images was developed.

When comparing the $X$-ray images of healing of long bone shaft defects fixed with one- and twoplane POLFIX stabiliser, it can be seen that the differences in healing appear as late as around the fourth week. In the two-plane fixation, new callus 
showing features of a plexiform bone covers the whole cross-section of the bone, whereas in the one-plane system the callus is located mainly on the opposite side of the plate, forming a classic 'banana syndrome'. This difference increases in time, which is visible in faster callus maturation (the distinct cortical bone - callus border disappears), however it takes place only within a smaller area (only on the opposite side of the plate). The two-plane fixation, on the other hand, creates conditions in which the callus, although maturating more slowly, covers the whole cross-section of the bone. This makes it possible for the fixation to be removed earlier. Another significant difference is a much intensive osteolysis around the outermost screws in the case of the one-plane fixation. The test results of the callus formation degree on the basis of an X-ray image analysis are listed in Table 1.

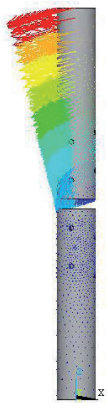

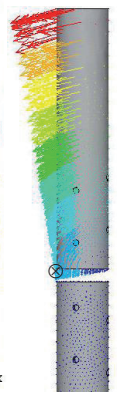

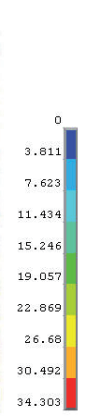

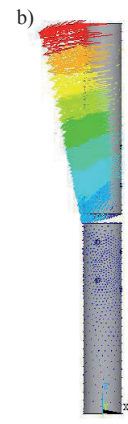

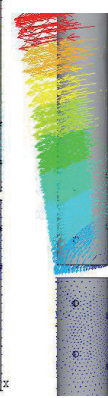

posite side of the plate. At the second level (the middle area of the bone), synostosis takes place more slowly than at the beginning. The callus at the third level located near the plate, is formed the least slowly.

In the case of the two-plane fixation, the callus formation coefficient increases evenly within the whole area of the bone cross-section (Fig. 5b). As a result, a complete fracture bone union was obtained at all levels in the 14th week.

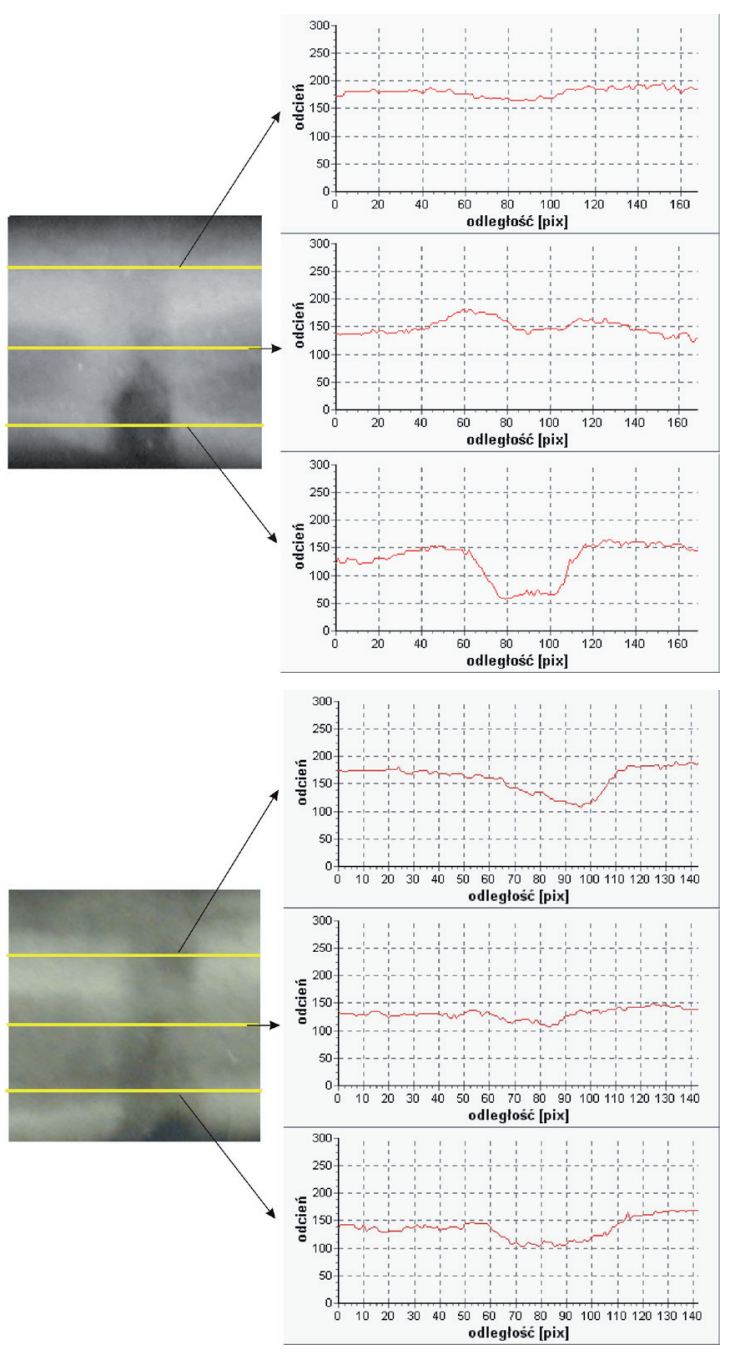

Fig. 4: Changes in greyness distribution at three levels (after ten weeks) for: a) one-plane, and b) two-plane fixations. levels are similar to a linear one.

The results of the callus formation coefficient for the one-plane fixation are illustrated in Figure 5a. It can be seen that the callus is formed faster at the first level, i.e. in the area located on the op- 
Table 1: The test results of the callus formation degree on the basis of an X-ray image analysis

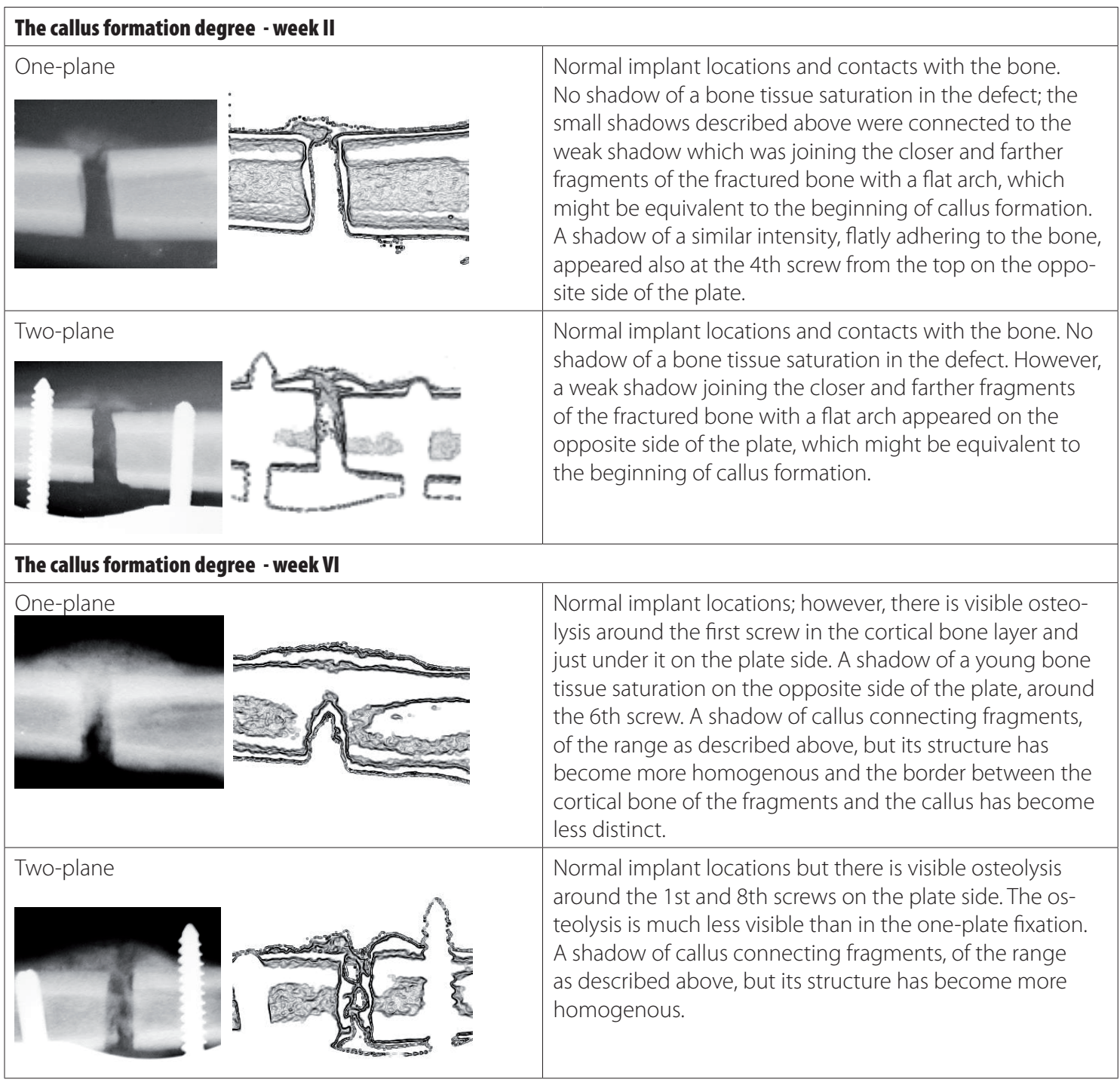
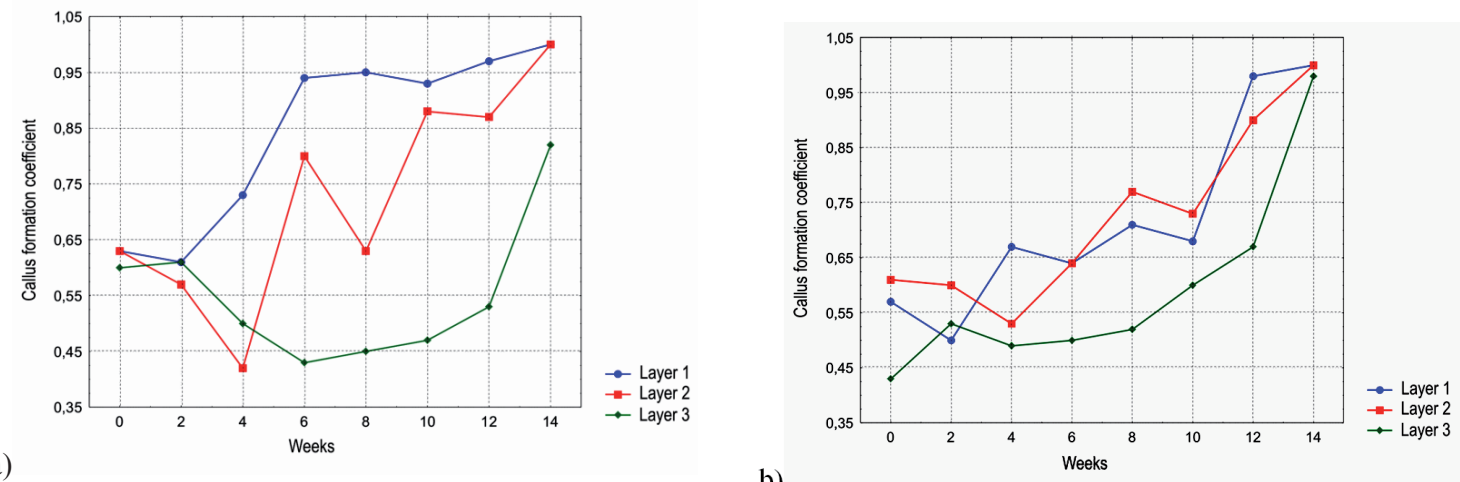

a)

b)

Fig. 5: Changes of callus formation coefficient in time: a) one-plane fixation, b) two-plane fixation 


\section{Discussion}

On the basis of the obtained results it can be concluded that applying two-plane plate stabilisers makes it possible to control fixation parameters to a large extent. At the same time, it has to be emphasised that even a small change of the stabilising system geometry might lead to a significant change in the conditions of the process of fractured bone union. It is thus necessary to investigate the details of biomechanics of such a fixation, and then develop instruments facilitating selection of an optimal configuration of plates and fixing screws. In terms of a two-plate fixation, the centre of rotation is located in the fracture crack. In this area the approach of bone fragments takes place. This effect is not of danger to the healing process, because there are no tangent forces present, which can destroy (as an effect of shearing) the bone tissue. The scheme of distortion vector distribution on the surface of the model shows that the system's centre of rotation is located in the fracture crack and in this area the approach of fracture fragments from the opposite side of the plate takes place, and distancing movement on the plate side. This type of distortion in the fracture crack stimulates formation of new bone tissue. From the obtained test results it can be noticed that application of twoplane fixation causes distortion of the fragment's centre of rotation to the fracture crack, at the same time allowing for better healing conditions. This is in accordance with literature data and it is also confirmed by clinical tests. Results of these tests show a significantly better and faster synostosis achieved through two-plate fixation.

On the basis of the results obtained from numerical tests supported by experimental verification and clinical observations, it may be concluded that the two-plane fixation of femoral bone fractures with the use of plate stabilisers constructed on the basis of the POLFIX system ensures better synostosis conditions than these provided by the traditional one-plane fixations. The two-plane fixations make it possible for most types of long bone fractures, especially femoral shaft fractures, to be healed faster. Moreover, fixations of this type al- low for widening the hitherto application range of plate stabilisers.

\section{References}

[1] CHAO E. Y. S., INOUE N., ELIAS J. J., ARO H., Enhancement of fracture healing by mechanical and surgical intervention, Clin. Orthop. Rel. Res., 1998, 355S, S163-S178.

[2] CLAES L. E., HEIGELE C. A., NEIDLINGER-WILKE C., KASPAR D., SEIDL W., MARGEVICIUS K. J., AUGAT P., Effects of mechnical factors on the fracture healing process, Clin. Orthop. Rel. Res., 1998, 355S, S132-S147.

[3] CUNNIGHAM J. L., The biomechanics of fracture fixation, Current Orthopaedics, 2001, 15, 457-464.

[4] GÁL, P., TOPORCER, T., VIDINSKÝ, B., HUDÁK, R., ŽIVČÁK, J., $\mathrm{SABO}$, J.: Simple interrupted percutaneous suture versus intradermal running suture for wound tensile strength measurement in rats: A technical note, European Surgical Research. Vol. 43, no. 1 (2009), p. 61-65. ISSN 0014-312X

[5] KRISCHAK G. D., JANOUSEK A., WOLF S., AUGAT P., KINZL L., CLAES L. E., Effects of one-plane and two-plane external fixation on sheep osteotomy healing and complications, Clin. Biomech., 2002, 17, 470-476.

[6] LACROIX D., PRENDERGAST P. J., A mechano-regulation model for tissue differentiation druring fracture healing: analysis of gap size and loading. J. Biomech., 2002, 35, 11631171.

[7] LIU Z. Q., AUSTIN T., THOMAS C. D., CLEMENT J. G., Bone feature analysis using image processing techniques, Comput. Biol. Med., 1996, 26, 65-76.

[8] LIU Z. Q., AUSTIN T., MOORE D., Image processing techniques for bone image analysis, IEEE, 1995, 458-461.

[9] MANN R.J., SARMIENTO A., Two-plate fixation of the femoral shaft, Clin. Orthop. Rel. Res., 1965, 38, 93-99.

[10] SIDUN J., PISZCZATOWSKI S., DĄBROWSKI J.R., MAZURKIEWICZZ., An estimation of displacement of two - plates long bones fixation, Acta of Bioengineering and Biomechanics, 2001, 3, Suppl. 1, 787-790.

[11] TÓTH, T., HUDÁK, R., GROMOŠOVÁ, S., MICHALÍKOVÁ, M., ŽIVČÁK, J., HUTNÍKOVÁ, L.: Mechanical property tests of biological tissues, Lékař a technika. Vol. 36, no. 2 (2006), p. 302-307. - ISSN 0301-5491

[12] WOJNAR L., TĘSIOROWSKI M., GĄDEK A., ZARZYCKI D., JASIEWICZ B., KĄCKI W., Zastosowanie kliniczne ilościowej oceny regeneratu kostnego na zdjęciach rentgenowskich, Przegląd Lekarski, 2002, 59, Suppl. 4, 120-122. 